JURNAL

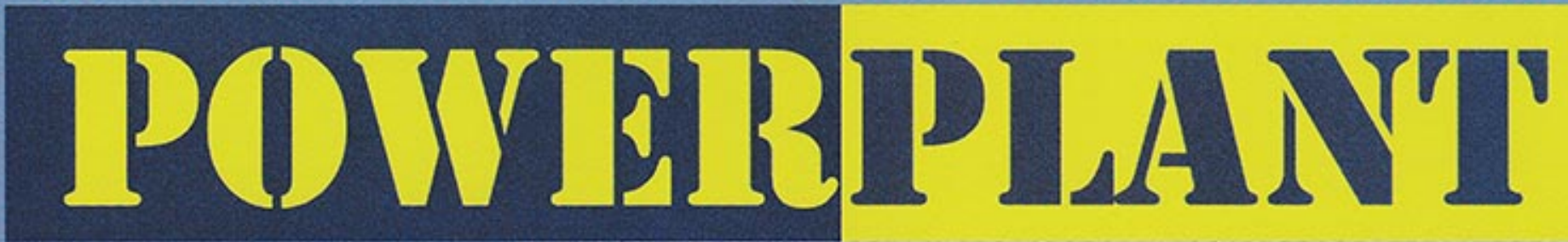

Roswati Nurhasanah

Jasmid Edy

Eza Brian Pradana

\section{Arief Suardi}

Vendy Antono

Al Asyi

Arisma Chairul Syarif Iman Kartolaksono R Jalu Eko Harjono

Nofirman

Yusuf Rasyid

Win Alfalah

Eko Sulistyo

Rahmat Ikhsan

Utami Wahyuningsih

Halim Rusjdi

Eko Sulistiyo

Sahlan

Jumiati

Intan Ratna Sari Yanti

Sri Yayi
Perancangan Boiler Dengan Memanfaatkan Sampah

Kering Untuk Bahan Bakar PLTU Mini 3 kW STT-PLN

Analisis Perbandingan Penggunaan Big Oil Gun dan Tiny Oil Gun terhadap Kosumsi Bahan Bakar Pada Saat Strat Up Unit di PLTU Banten Lontar

Uji Prestasi dan Emisi Diesel Berbahan Bakar Minyak Nabati Murni untuk Pembangkitan Daya di Daerah Terpencil

Pengukuran Suhu Pembakaran di Dalam Boiler : Pirometer Akuistik VS Pirometer Infared

Pengaruh Pemeliharaan Overhoul Turbo Charger

Terhadap Kinerja Mesin Unit VII PLTD Ampenan

Penanggulangan Korosi Pada Pipa Gas Dengan Metode Catodic Protection (Anoda Karbon) PT PGN Solution Area Cengkareng

Analisis Strategi Teknologi PLTS Fotovoltik di Indonesia Terhadap Nilai Eqivalensi dan Pemanfatan Per Wilayah

Pengembangan Model Pembelajaran Berbasis Tutorial Bagi Mahasiswa Teknik Mesin STT PLN

\begin{tabular}{|c|c|c|c|c|c|c|}
\hline 111 & & $\mathrm{SE}$ & OLAH & INGGI TEY & PLN (STT-PLN) & \\
\hline$\||\|||| \mid$ & JURNAL POWERPLANT & VOL. 5 & NO. 1 & HAL. 1.63 & NOVEMBER 2017 & ISSN No :2356-1513 \\
\hline
\end{tabular}




\title{
PENGARUH PEMELIHARAAN OVERHAUL TURBOCHARGER TERHADAP KINERJA MESIN UNIT VII PLTD AMPENAN
}

\author{
Win Alfalah $^{1)}$, Eko Sulistyo ${ }^{2)}$, Rahmat Ikhsan ${ }^{3)}$ \\ 1,2,3) Jurusan Teknik Mesin Sekolah Tinggi Teknik PLN \\ email: winalfalah@sttpln.ac.id \\ email: ekosulistyo@sttpln.ac.id
}

\begin{abstract}
Increasing number of Indonesian population and unequal distribution of population with higher densities only on certain islands rather than outside the islands, appropriate development strategies are needed in providing need for electrical resilience for the population. Frequent interactions with fuel - powered engines such as diesel engines and human resource readiness probably are reasons for government choice in using diesel powered engines (very big and medium sized diesel engines) to provide electricity on small islands and remote islands. Availability of electrical energy will create a conducive investment climate and improve welfare of the population. Lombok West Nusa Tenggara is one of small islands in Indonesia. In the area, electricity need is generated by PLTD Ampenan. One of the Ampenan diesel engines in unit VII is New Sulzer 12 ZAV 40 S equipped with double turbocharger type VTR 354. To maintain its performance, overhauls done routinely. Overhaul is a procedure performed to restore engine performance to factory standard specification value and give second age with condition worn or defective components refer to reusable parts instructions according to factory standards. This research focuses on the state of the diesel engine as a prime mover of generator before and after its turbocharger overhaul. And also, things about turbocharger overhaul and its effect on the engine.
\end{abstract}

Keywords: turbocharger, overhaul, maintenance, engine, diesel

\section{PENDAHULUAN}

Semakin bertambahnya jumlah penduduk Indonesia dan distribusi penduduk yang tidak merata dengan tingkat kepadatan yang tinggi hanya di pulau - pulau tertentu dibandingkan di luar pulau - pulau itu, strategi pembangunan yang tepat diperlukan dalam menyediakan kebutuhan ketahanan listrik bagi masyarakat. Pembangunan ketahanan listrik merupakan salahsatu pilar penopang kesejahteraan masyarakat, di mana peran ilmu pengetahuan dan teknologi harus diposisikan secara nyata dalam setiap kegiatan pembangunan listrik.

Pada Agustus 2017, telah tersebar 722 mesin PLTD di 241 lokasi dengan kapasitas 443 MW di daerah terpencil dan pulau terluar di seluruh Indonesia yang sebagian sudah beroperasi. Pembangkit listrik tenaga diesel (PLTD) menjadi pilihan pemerintah yang paling utama untuk penuhi kebutuhan listrik di wilayah perbatasan dan pulau terluar. Pulau kecil selama ini dialiri listrik oleh pembangkit listrik tenaga diesel.
Permasalahan ketersediaan listrik di pulau pulau kecil ataupun pulau terdepan di Indonesia telah menjadi masalah yang berlarut - larut. Keterbatasan listrik tentu akan membuat aktivitas masyarakat menjadi terbatas. Pasokan listrik di pulau - pulau kecil umumnya dibangkitkan oleh generator diesel (genset). Pemakaian genset ini tentu akan menghabiskan bahan bakar minyak yang tidak sedikit, sehingga dapat dikatakan tidak efisien untuk mencukupi kebutuhan listrik masyarakat pulau sehari - hari. Pemborosan pemakaian listrik di pulau - pulau kecil tersebut kemudian diatasi dengan pembatasan waktu penggunaan listrik, yaitu listrik hanya menyala pada pukul 17:00 sampai pukul 07:00 keesokan harinya. untuk memenuhi kekurangan pasokan listrik di pulau - pulau kecil dan pulau - pulau terpencil.

Seringnya interaksi (kesiapan SDM) terhadap mesin pembakaran dalam (salahsatunya mesin diesel) dan alasan ketersediaan jenis dan suku cadang yang sangat banyak mungkin menjadi alasan pemerintah memilih mesin diesel besar dan sangat besar sebagai tenaga pembangkit listrik di Indonesia 
mungkin adalah alasan pilihan pemerintah dalam menggunakan mesin tenaga diesel untuk menjadi pembangkit tenaga listrik di pulau pulau kecil dan pulau - pulau terpencil, seperti di Lombok, Nusa Tenggara Barat. Selain itu, kesiapan tenaga ahli, dana, sarana, dsb. mungkin juga menjadikan pemerintah lebih memilih mesin diesel sebagai tenaga yang saat ini masih utama dibandingkan energi terbarukan, seperti matahari, angin, dsb.

Bila ketersediaan listrik baik di suatu daerah, berbagai kegiatan akan tumbuh, industri kecil, menengah bahkan besar akan muncul dan memberikan lapangan pekerjaan. Ketersediaan energi listrik akan menciptakan iklim investasi yang kondusif serta meningkatkan kesejahteraan masyarakat.

\section{KAJIAN LITERATUR DAN PENGEMBANGAN HIPOTESIS}

Pembangkit Listrik Tenaga diesel (PLTD) ialah Pembangkit listrik yang menggunakan mesin diesel sebagai penggerak utama (prime mover). Prime mover merupakan peralatan yang mempunyai fungsi menghasilkan energi mekanis yang diperlukan untuk memutar rotor generator. Mesin diesel sebagai penggerak utama PLTD berfungsi menghasilkan tenaga mekanis yang dipergunakan untuk memutar rotor generator.

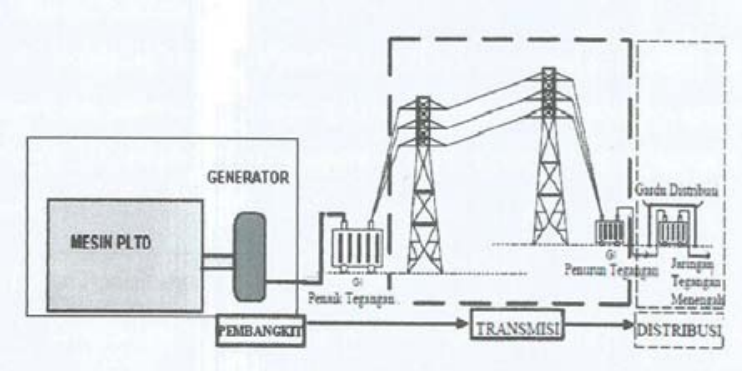

Gambar 1. Pembangkit Listrik Tenaga Diesel

PLTD merupakan suatu instalasi pembangkit listrik yang terdiri dari suatu unit pembangkit (SPD) dan sarana pembangkitan. Mesin diesel sebagai penggerak utama untuk mendapatkan energi listrik dan dikeluarkan oleh generator. Pada mesin diesel, energi bahan bakar diubah menjadi energi mekanik dengan proses pembakaran di dalam mesin itu sendiri. Mesin diesel pada saat ini sudah banyak mengalami perkembangan dalam pemakaian untuk angkutan darat dan laut, kemudian pembangkitan dalam daya kecil dan menengah bahkan sampai daya besar sudah ada yang menggunakannya. Untuk mempermudah dalam melakukan pemeliharaan mesin diesel, para teknisi harus mempunyai dasar - dasar pengetahuan mengenai mesin diesel yang baik, agar setiap melakukan pemeliharaan para teknisi dapat memperlakukan setiap komponen yang berada dalam mesin, sesuai dengan konstruksinya.

Yang dimaksud dengan unit PLTD adalah kesatuan peralatan - peralatan utama dan alat alat bantu serta perlengkapannya yang tersusun dalam hubungan kerja, membentuk sistem untuk mengubah energi yang terkandung didalam bahan bakar minyak menjadi tenaga mekanis dengan menggunakan mesin diesel sebagai penggerak utamanya. Lalu, tenaga mekanis tersebut oleh generator diubah menjadi tenaga listrik.

Salahsatu mesin PLTD Ampenan di unit VII adalah New Sulzer 12 ZAV $40 \mathrm{~S}$ dan Turbocharger Type VTR 354 yang dilengkapi dengan turbocharger. Turbocharger untuk menghasilkan keluaran tenaga yang lebih tinggi, tingkat emisi yang lebih rendah,

Mesin diesel biasa hampir pasti memiliki output daya yang lebih rendah daripada mesin diesel dengan turbocharger. Faktor - faktor ini memberikan mesin diesel biasa miskin rasio tenaga per berat. Berat unit turbocharger sangat kecil tetapi menawarkan kenaikan torsi dan peningkatan efisiensi yang signifikan.

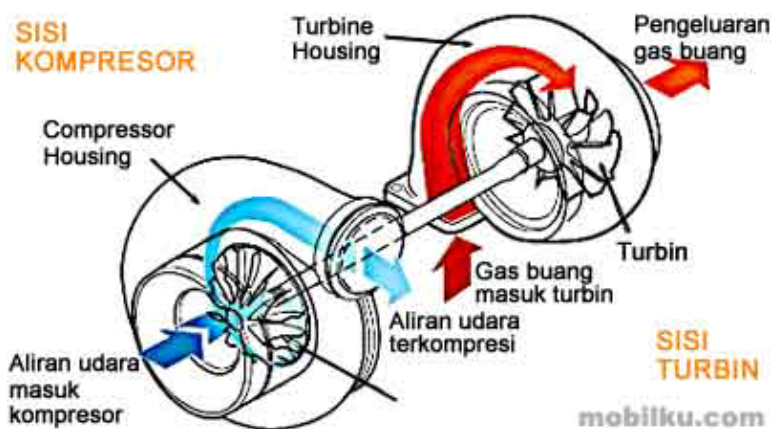

Gambar 2. Cara kerja turbocharger pada mesin

Turbocharger juga didefinisikan sebagai salah satu komponen tambahan pada motor pembakaran dalam baik itu motor bensin maupun motor diesel yang berfungsi untuk meningkatkan mass flow yang masuk ke dalam engine, sehingga power yang dihasilkan dapat meningkat. Komponen utamanya terdiri dan turbin dan kompresor. Turbin pada turbocharger 
digerakkan oleh gas exhaust engine, kemudian putaran turbin yang dihasilkan menggerakkan kompresor untuk meningkatkan mass flow udara yang masuk ke mesin dan menjadikan mesin sangat efisien dan konsumsi bahan bakar yang ekonomis pada perbandingan tekanan kompresor dan turbin yang tinggi.

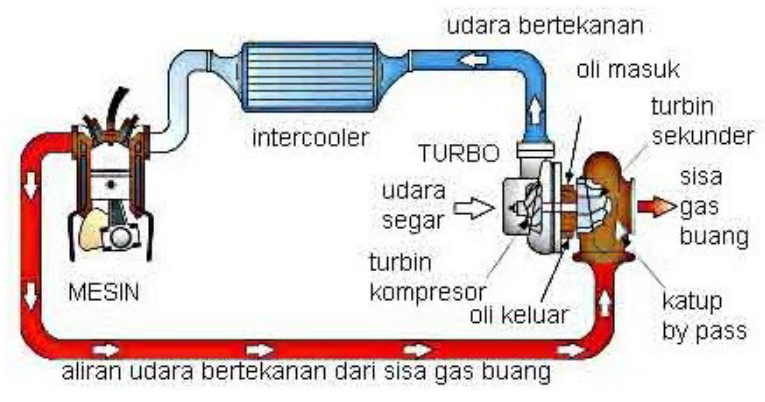

Gambar 3. Turbocharger dilengkapi dengan intercooler

Pada saat udara didorong masuk oleh turbocharger, tekanan udara tersebut juga meningkat. Karena tekanannya meningkat, suhu udara segar dari lingkungan yang dipompa (dikompresi) oleh turbocharger juga meningkat dan akan memperburuk mesin jika udara yang disuplai merupakan udara yang terlalu panas. Jika hal tersebut sampai terjadi, suhu ruang bahan bakar akan meningkat dan dapat terjadi overheating serta akan membuat udara memuai sehingga kepadatan udara berkurang. Hal tersebut dapat mempengaruhi kinerja terutama tenaga mesin karena pembakaran tidak terjadi secara sempurna karena kepadatan udara rendah akibat pemuaian. Untuk menghindari hal tersebut, intercooler menjadi solusi yang cukup ampuh. Intercooler bekerja sebagai pelepas panas udara yang telah ditekan kompresor turbocharger.

Hipotesis penulis terhadap hasil penelitian adalah dengan adanya overhaul turbocharger, turbocharger akan kembali ke kondisi standar pabrik karena hilangnya kotoran di turbocharger, komponen - komponen turbocharger yang baru/seperti baru, penggantian oli, dll. Hal - hal ini menyebabkan gaya gesek turbocharger berkurang jauh, sehingga putaran rotor turbocharger akan meningkat. Hal ini menyebabkan debit udara yang masuk akan menjadi lebih banyak. Banyaknya udara ini akan mengakibatkan tekanan di dalam ruang bakar tinggi. Sebagai akibatnya, piston ditekan oleh udara yang bertekanan tinggi ini meskipun sebelum ledakan bahan bakar. Hal ini mengakibatkan kecepatan mesin bertambah. Setelah ledakan bahan bakar, tekanan udara yang ada di ruang bakar ini meningkat lagi nilai tekanannya, sehingga efisiensi mesin meningkat jauh.

Dengan adanya penambahan oksigen (karena debit udara meningkat) dan kecepatan berbaurnya solar ke udara di ruang bakar meningkat (karena tekanan udara setelah overhaul membesar dibandingkan sebelumnya), pembakaran mesin menjadi lebih sempurna. Oleh karena itu, tenaga hasil ledakan bahan bakar juga menjadi lebih besar.

\subsection{Teori Pemeliharaan Mesin PLTD 2.1.1 Defenisi Pemeliharaan}

Melakukan segala aktivitas terhadap PLTD, untuk mempertahankan unjuk kerja semula atau mengembalikan kepada kondisi semula secara optimal, agar aset fisik (PLTD) tersebut dapat memenuhi syarat fungsinya sesuai tujuan dan sasarannya.

\subsubsection{Tujuan Pemeliharaan}

Sebagaimana peralatan pada umumnya, maka peralatan yang beroperasi dalam sistem pembangkit listrik harus dipelihara secara rutin sesuai dengan buku manual pemeliharaan pabrik. Pemeliharaan PLTD dilakukan untuk mempertahankan kinerja optimal yang telah ditetapkan atau mengembalikan pada keadaan seperti baru (minimal memenuhi standar) agar PLTD dapat beroperasi dengan efisien, ekonomis dan handal.

\subsubsection{Sasaran Pemeliharaan}

Sasaran pemeliharaan PLTD diarahkan untuk mencapai:

a. Jam operasi lebih besar dari 6000 jam pertahun.

b. Kapasitas mampu kontinu lebih besar dari 80\% dari kapasitas terpasang.

c. Mempertahankan tingkat efsiensi pemakaian bahan bakar dan pelumas sesuai spesifikasinya.

d. Biaya pemeliharaan pada batas - batas yang ekonomis.

e. Mempertahankan tingkat keamanan dan keselamatan kerja.

\subsubsection{Jenis - Jenis Pemeliharaan}

\section{Pemeliharaan Preventif (Preventif Maintenance)}

Pada awalnya preventif maintenance adalah perawatan yang dilakukan secara berkala dalam 
rangka mencegah terjadinya kerusakan dengan melakukan pengecekan, penggantian, overhaul pada sistem interval waktu yang ditentukan. Jenis perawatan ini mulai dikenal sejak dimulainya era perang dunia kedua yaitu ketika dunia membutuhkan mekanisasi yang berlebihan pada semua jenis industri. Mengingat jenis mesin makin banyak dan kompleks, maka down time menjadi masalah, sehingga industri membutuhkan cara untuk mencegah kerusakan. Dari sinilah timbul ide overhaul pada interval waktu yang tetap. Selain itu, disebabkan oleh biaya perawatan asset yang makin meningkat terhadap produksi maka lahirlah sistem perencanaan dan kontrol perawatan (maintenance planning and control system). Sistem ini telah sangat mapan dalam praktek perawatan.

Pemeliharaan preventif untuk pembangkit listrik PT PLN (Persero) mempunyai periode waktu tertentu yaitu dari P6 (6000 jam = top overhaul), P7 (12000 jam = small overhaul), dan P8 (18000 jam = major overhaul).

\section{a. Top Overhaul (TO 6000 jam)}

Pemeliharaan 6000 jam terhadap bagian atas mesin (silinder head keatas) yang meliputi pekerjaan pengukuran, penggantian atau merekondisi komponen $\neg$ komponen yang aus untuk mendapatkan kondisi operasi yang optimal. pekerjaan - pekerjaan yang dilakukan pada top overhaul meliputi pemeriksaan pada seluruh bagian - bagian unit yang antara lain :

1. Pemeriksaan semua kepala silinder dan komponen yang lainnya.

2. Pemeriksaan dan pengukuran satu bantalan dan bantalan luncuran (metal) atau sesuai buku manual pabrikan.

3. Pembersihan generator

4. Pemeriksaan peralatan listrik

5. Pemeriksaan perawat pendingin cooler dan inter cooler

6. Pemeriksaan cairan peredam getaran (vibration damper)

7. Pemeriksaan turbocharger (overhaul jika diperlukan pada saatnya)

8. Pengetesan kemampuan mesin

\section{b. Semi Overhaul (SO 12000 jam)}

Pemeriksaan 12000 jam terhadap bagian connecting rod keatas yang meliputi pengukuran, penggantian atau merekonduksi komponen yang aus untuk mendapatkan operasi yang optimal. pekerjaan yang dilaksanakan pada Top Overhaul meliputi pemeriksaan pada seluruh bagian unit antara lain: Semi Overhaul untuk putaran $<750 \mathrm{rpm}$.

Pemeliharaan 18000 jam terhadap bagian mesin yang meliputi pekerjaan pengukuran, penggantian atau merekondisi komponen yang aus untuk mendapatkan kondisi operasi yang optimal. Pekerjaan yang dilaksanakan pada top overhaul meliputi pemeriksaan bagian unit antara lain :

1. Overhaul kepala silinder (silinder head) seluruhnya dan pemeriksaan komponennya.

2. Overhaul piston, silinder, bantalan, turbocharger dan silinder blok

3. Pemeriksaan perlengkapan/peralatan bantu, generator dan panel listrik, pondasi getaran/suara.

4. Pengetesan kemampuan mesin.

\section{Pemeliharaan Prediktif}

Dilakukan berdasarkan identifikasi kegagalan yang berpotensi terjadi dan digunakan selanjutnya untuk mencegah hal - hal yang menyebabkan terjadinya kegagalan. Agar pemeliharaan ini memberikan manfaat terhadap aset maka harus ada perubahan kondisi yang dapat diukur, yang mengindikasikan ada atau tidaknya kegagalan. Metode ini diterapkan untuk mengukur kondisi yang bersifat tanpa gangguan.

\section{Pemeliharaan Korektif}

Pemeliharaan korektif dilakukan apabila terjadi kegagalan berulang pada suatu mesin atau komponen mesin dalam rangka mencegah jangan sampai terulang kembali di masa depan dengan melakukan studi (reverse engineering), merancang ulang, menetapkan kembali spesifikasi material, memasang dan menguji komponen yang gagal tersebut.

Pemeriksaan korektif (tidak periodik) mencakup:

1. Perbaikan

2. Pemeliharaan tidak periodik, meliputi pekerjaan rekondisi dan perbaikan beberapa komponen dengan mengembalikan kepada kondisi semula atau maksimal.

3. Penggantian

4. Pemeliharaan ini meliputi pekerjaan rekondisi dan penggantian sejumlah besar dengan tujuan mengembalikan kepada kondisi semula maksimal.

5. Penyempurnaan

6. Pemeliharaan ini meliputi pekerjaan perubahan desain dari komponen dengan 
tujuan menaikkan kemampuan dan efisiensi.

7. Pemeliharaan break down (turun mesin)

Breakdown maintenance adalah perawatan yang dilakukan ketika sudah terjadi kerusakan pada mesin atau peralatan kerja, sehingga mesin tersebut tidak dapat beroperasi secara normal atau terhentinya operasional secara total dalam kondisi mendadak. Breakdown maintenance ini harus dihindari karena akan terjadi kerugian akibat berhentinya mesin produksi yang menyebabkan tidak tercapai kualitas ataupun output produksi.

\section{METODE PENELITIAN}

\subsection{Alur Penelitian}

Alur penelitian yang dijalankan adalah sebagai berikut:

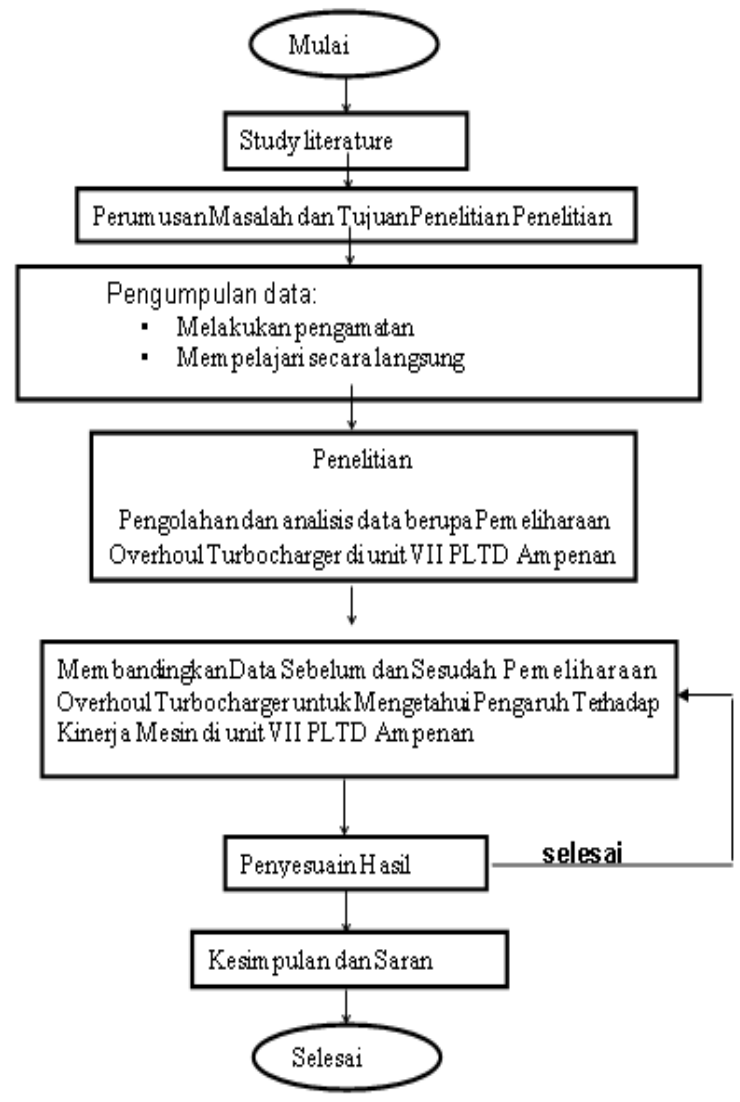

Gambar 4. Skema Alur Penelitian

\subsection{Objek Penelitian}

Objek penelitian ini adalah motor diesel

PLTD Ampenan unit VII, yaitu New Sulzer 12 ZAV $40 \mathrm{~S}$ dengan double turbocharger tipe VTR 354.

- $\quad$ Enam variasi kondisi untuk data temperatur udara setelah melewati kompresor turbocharger, yaitu: sebelum dan setelah overhaul turbocharger pada beban 1,9 MW, 3,8 MW dan 5,7 MW.

- Enam variasi kondisi untuk data tekanan udara setelah melewati kompresor turbocharger, yaitu: sebelum dan setelah overhaul turbocharger pada beban 1,9 MW, 3,8 MW dan 5,7 MW.

- $\quad$ Enam variasi kondisi untuk data temperatur hasil pembakaran: sebelum dan setelah overhaul turbocharger pada beban 1,9 MW, 3,8 MW dan 5,7 MW.

- Enam variasi kondisi untuk data putaran rotor turbocharger kiri dan kanan (L/R): sebelum dan setelah overhaul turbocharger pada beban 1,9 MW, 3,8 MW dan 5,7 MW.

- Enam variasi kondisi untuk data putaran mesin diesel: sebelum dan setelah overhaul turbocharger pada beban 1,9 MW, 3,8 MW dan 5,7 MW. 


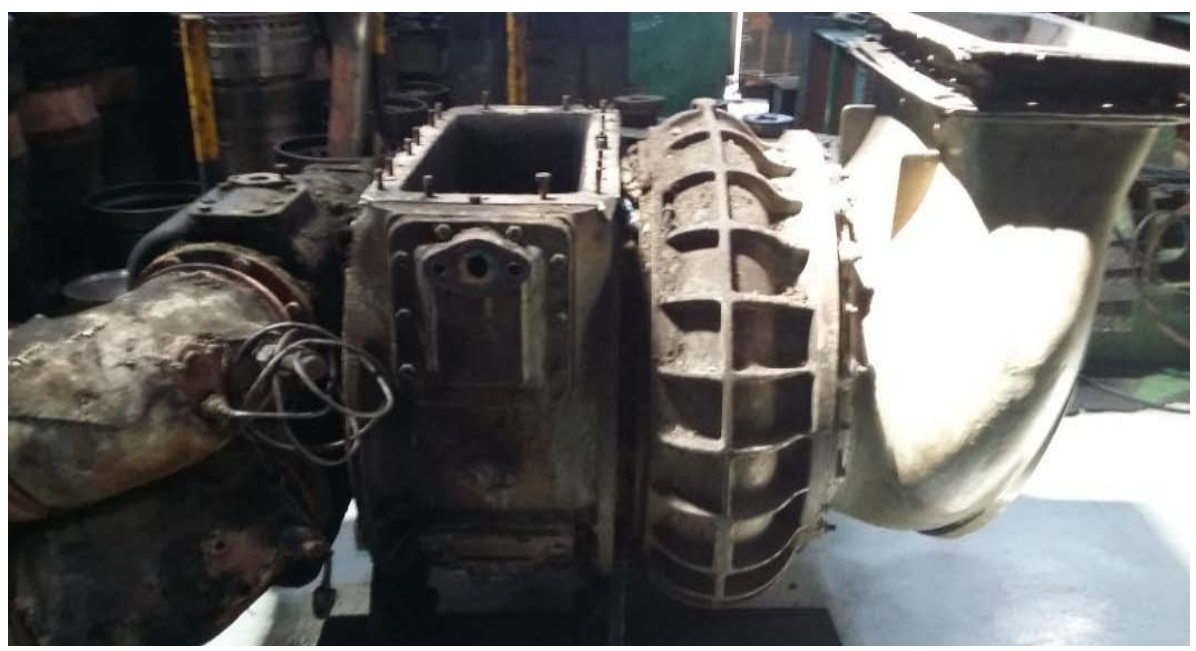

Gambar 5. Turbocharger Type VTR 354 (PLTD Ampenan unit VII)

\section{HASIL DAN PEMBAHASAN}

\subsection{Perbandingan Data Temperatur dan Tekanan Turbocharger Sebelum dan Sesudah Overhoul}

Perbandingan data temperatur dan tekanannya ini sendiri dilakukan dengan cara membandingkan data sebelum dan sesudah pemeliharaan dengan memperhatikan data temperatur standar dari keluaran dari turbocharger setiap beban pada unit VII. Untuk data temperatur turbocharger setiap bebannya sudah di tentukan standar minimumnya yaitu untuk beban 1,9 MW temperaturnya $\left(250^{\circ} \mathrm{C}\right)$, kemudian beban $3,8 \mathrm{MW}\left(340^{\circ} \mathrm{C}\right)$, untuk beban 5,8 MW $\left(460^{\circ} \mathrm{C}\right)$.

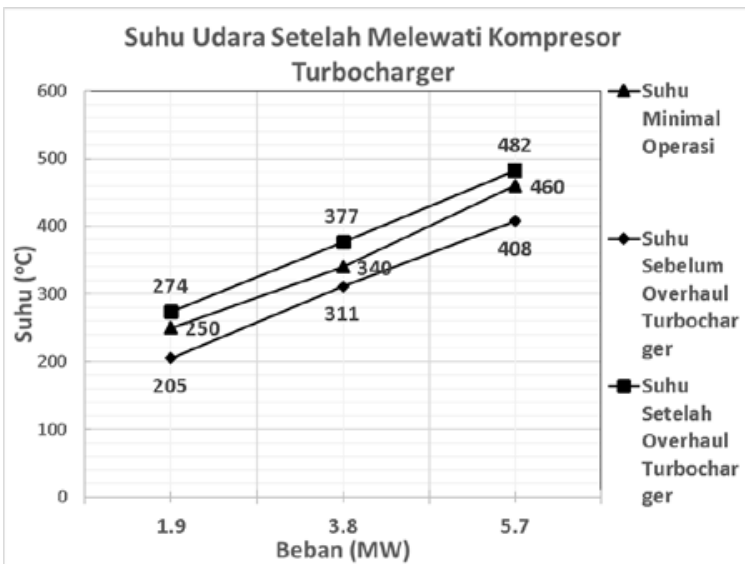

Gambar 6. Grafik suhu udara keluaran kompresor turbocharger

Sebelum dilakukan pemeliharan turbocharger data temperatur aktual operasi data menunjukkan bahwa temperatur berada di bawah standar minimum keluaran kompresor turbocharger. Hal ini dapat menyebabkan pembakaran dalam ruang bakar kurang sempurna, penurunan temperatur turbocharger biasanya disebabkan oleh banyaknya kerak kotoran yang menempel pada sudu kompresor dan turbin turbocharger, terjadi gangguan pada bearing bantalan sehingga putaran dari rotor turbin dan kompresor menjadi berat. Nilai putaran yang kurang menyebabkan udara yang dikompresi menjadi lebih sedikit, maka temperatur udara yang dikompresi tersebut menjadi kurang. Oleh karena itu, dilakukan pembersihan pada sudu kompresor dan turbin turbocharger dan bearing bantalan diganti, dan dilakukan pemeliharaan lainnya pada turbocharger.

Setelah dilakukan pemeliharan turbocharger data temperatur menunjukkan terjadi peningkatan temperatur yang sebelumnya $205^{\circ} \mathrm{C}$ kemudian naik menjadi $274^{\circ} \mathrm{C}$ melewati temperatur standar minimum $250^{\circ} \mathrm{C}$ temperatur keluaran turbocharger untuk beban 1,9 MW. Untuk beban 3,8 MW, terjadi peningkatan temperatur juga yang sebelumnya $311^{\circ} \mathrm{C}$ kemudian naik menjadi $377^{\circ} \mathrm{C}$ melewati temperatur standar minimum $340^{\circ} \mathrm{C}$ temperatur keluaran turbocharger. Untuk beban 5,7 MW peningkatan temperaturnya dari juga yang sebelumnya $408^{\circ} \mathrm{C}$ kemudian naik menjadi $482^{\circ} \mathrm{C}$ melewati temperatur standar minimum $360^{\circ} \mathrm{C}$ temperatur keluaran turbocharger. Dapat di simpulkan bahwa pemeliharaan turbocharger hasilnya sesuai dengan target karena bisa melewati batas minimum keluaran kompresor turbocharger. 


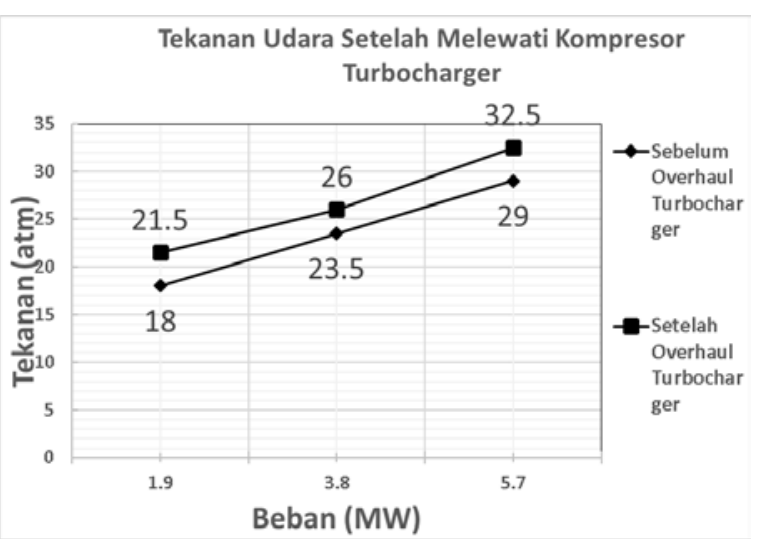

Gambar 7. Grafik tekanan udara keluaran kompresor turbocharger

Penurunan tekanan kompresor turbocharger terjadi karena penurunan putaran turbocharger. Hal ini diakibatkan kotoran pada rotor dan nozzle turbocharger, dll. Kotoran pada rotor membuat putaran rotor melambat dan jadi tidak seimbang aibatnya gaya gesek besar. Sedangkan, kotoran pada nozzle membuat udara di turbocharger tergesek dengan kotoran, sehingga mengakibatkan aliran yang tidak terlalu laminer. Setelah dilakukan pembersihan dan penambahan oli pada turbocharger tersebut, gesekan pada putaran rotor turbocharger berkurang, sehingga putaran menjadi lebih cepat. Hal ini menyebabkan lebih banyak udara yang dikompresi kompresor turbocharger, maka tekanan keluaran turbocharger meningkat setelah dilakukan overhaul karena tekanan berbanding lurus dengan jumlah udara yang bisa dikompresi dalam satu waktu.

Ditambah lagi dengan pembersihan intercooler, pertukaran kalor dapat terjadi lebih baik, sehingga suhu yang lebih rendah dapat dicapai dengan jumlah udara yang sama. Hal ini disebabkan setelah melalui kompresor, intercooler mendinginkan udara tersebut, sehingga volume udara menyusut. Oleh karena itu, pada jumlah udara yang sama, tekanan dapat diperoleh menjadi lebih rendah. Pada kondisi setelah overhaul, debit udara yang dikompresi oleh turbocharger meningkat jauh, sehingga tekanan udara setelah melalui intercooler dapat melewati sebelum overhaul, meskipun sudah diturunkan tekanannya akibat pendinginan intercooler (temperatur yang turun menurunkan tekanan juga), sehingga penurunan tekanan udara akibat pembersihan intercooler hanya tersirat.

\subsection{Masalah - Masalah yang Terjadi di Turbocharger - Turbocharger PLTD Ampenan unit VII}

Salahsatu gangguan pada turbocharger PLTD Ampenan adalah penggunaan gas buang kurang efektif karena banyak kotoran pada sudu turbin. Banyaknya kotoran membuat putaran turbocharger terhambat akibat tingginya gaya gesek. Penurunan putaran turbocharger baik di sisi turbin maupun di sisi kompresor menurunkan efisiensi penggunaan turbocharger. Hal ini dapat diatasi dengan overhaul karena pada overhaul, bagian - bagian turbocharger juga dibersihkan.

Selain rotor turbocharger kotor, menurunnya beban (nilai putaran per menit) mesin diesel yang secara mendadak dilakukan dan penumpukan kotoran di intake turbocharger maupun di saluran keluar turbocharger (menuju ruang bakar) dapat menyebabkan masalah lain, yaitu surging pada turbocharger.

Surging adalah fenomena terjadinya tekanan balik dari udara yang melewati kompresor turbocharger (saluran menuju ruang bakar). Tekanan balik itu mengarah ke saluran udara sebelum kompresor turbocharger, sehingga putaran rotor turbocharger terhambat. Hal ini terjadi saat penurunan beban mesin diesel secara mendadak. Karena pembakaran diesel saat beban yang lebih rendah (nilai putaran per menit generator) membutuhkan lebih sedikit udara terkompresi, maka sebagian dari debit yang besar udara terkompresi dari turbocharger tidak terpakai/tidak bisa masuk ke ruang bakar karena penurunan beban (nilai putaran per menit) mesin diesel. Hal ini menyebabkan tekanan balik yang arahnya berlawanan dengan putaran turbocharger Sebagai akibatnya, ada gaya puntir yang besar pada turbocharger, sehingga turbocharger bisa lebih cepat rusak. Surging dapat juga terjadi akibat gangguan pendinginan udara setelah melalui kompresor turbocharger.

Selain penurunan putaran mesin secara drastis dan mendadak, kerusakan dan kotornya intercooler di PLTD Ampenan juga dapat menyebabkan surging pada turbocharger. Kompresor turbocharger mengompresi sejumlah besar udara yang menyebabkan suhunya tinggi akibat kompresi tekanan tinggi. Intercooler berfungsi sebagai penurun suhu tinggi udara tersebut sebelum masuk ruang bakar, sehingga kalau intercooler rusak, suhu udara tersebut tidak turun. Penurunan suhu udara menyebabkan tekanan udara menurun 
(sifat termal zat). Saat intercooler rusak, suhu udara setelah melewati kompresor tetap tinggi, sehingga tekanan tetap tinggi. Karena tekanan tinggi di saluran setelah melewati kompresor inilah, surging terjadi di sisi kompresor turbocharger. Solusinya lakukan pembersihan pada intercooler dan memastikan bahwa sistem pendingin berfungsi optimal, terkadang ada benda - benda yang tidak diinginkan masuk ke dalam pipa system intercooler, sehingga menghalangi aliran air pendinginan. Kegagalan intercooler juga dari pompa sistem pendingin tidak bekerja optimal.

Pemeliharaan turbocharger pada saat unit beroperasi untuk pembersihan kompresor menggunakan metode air bersih diinjeksikan ke dalam ruang kompresor untuk turbin ada dua metode, yaitu kering dengan menggunakan media arang dgn syarat temperatur yang masuk dalam turbin di atas $490^{\circ} \mathrm{C}$ dan basah menggunakan media air hangat syarat temperatur masuk turbin di bawah $330^{\circ} \mathrm{C}$.

Ketika bearing turbocharger bermasalah (rusak atau kotor), gaya gesek rotor turbocharger akan meningkat. Akibat kerugian gaya gesek ini, efisiensi turbocharger berkurang. Oleh karena itu, harus dilakukan pembersihan atau penggantian bearing. Hal ini disebabkan oleh terjadi keausan atau kelonggaran pada bearing bantalan, kerusakan bearing bantalan bisa terjadi karena kurangnya minyak pelumasan dan sering terjadinya fenomena surging atau penyebab lainnya, seperti faktor dari umur penggunaan bearing tersebut. Solusinya dilakukan penggantian bearing. Bearing yang bermasalah juga menyebabkan rotor bergoyang - goyang. Jika rotor terkena casing akan mengakibatkan kerusakan rotor turbocharger.

Keausan pada bantalan turbocharger disebabkan oleh penggantian minyak pelumas dan turunnya level minyak pelumas pada batas normalnya, seperti yang kita tahu bahwa fungsi dari minyak pelumas ini sendiri selain sebagai pelumasan juga berfungsi sebagai media pendingin dari bearing bantalan guna mencegah terjadi nya keausan pada bearing bantalan. Solusinya di lakukan penggantian rutin pada minyak pelumas setiap 1000 jam sekali dan dilakukan pengecekan minyak pelumas setiap kali unit mau dioperasikan guna mengetahui level minyak pelumas pada batas normal.

Ketika sudu kompresor kotor, udara yang masuk ke ruang bakar juga kotor. Udara kotor dapat menambah gesekan piston karena ledakan di ruang bakar yang terjadi menyebabkan penyebaran kotoran dari udara kotor tadi ke bagian - bagian di ruang bakar. Hal ini bisa dicegah dengan cara melakukan pembersihan pada sudu kompresor dan saringan udara masuk turbocharger.

Selain hal - hal di atas, di PLTD Ampenan juga terjadi permasalahan di pelumasan. Dalam oli terdapat sisa - sisa gesekan bagian mesin, kandungan air akibat pengembunan, senyawa senyawa lain yang terbentuk di dalam mesin, dsb. Penggantian oli yang terlambat/lebih dari jam operasi oli berarti membiarkan mesin berjalan dengan hal - hal tadi, sehingga gesekan dan reaksi kimiawi akibat zat - zat yang ada terjadi dengan banyak dan berantai. Ini menyebabkan berkurangnya umur mesin secara signifikan. Selain itu, pemilihan jenis oli (kekentalan dan sifatnya) yang salah dapat menyebabkan kerugian - kerugian pada mesin, misalnya keausan dan sebagainya. Oleh karena itu, pemilihan jenis oli harus tepat dan masa penggantian oli juga harus diperhatikan.

\subsection{Beban Keluaran Unit 1,9 MW Sebelum dan Setelah Overhaul Turbocharger}

Data sebelum dilakukan pemeliharaan overhoul turbocharger untuk daya 1,9 MW adalah putaran mesin $503 \mathrm{rpm}$, frekuensi getaran 49,8 Hz, dan untuk putaran turbocharger adalah $12.500 \mathrm{rpm}$. Untuk temperatur gas setelah pembakaran di dalam silinder 1 sampai 6 sisi A rata rata $332{ }^{\circ} \mathrm{C}$ dan sisi $\mathrm{B} 323{ }^{\circ} \mathrm{C}$, temperatur gas buang masuk ke dalam turbin turbocharger sisi A $317^{\circ} \mathrm{C}$ dan keluar dari turbin $305{ }^{\circ} \mathrm{C}$, sisi $\mathrm{B}$ turbin turbocharger udara gas buang masuk $327^{\circ} \mathrm{C}$ dan keluar turbin $313^{\circ} \mathrm{C}$.

Kemudian setelah dilakukan pemeliharaan overhoul turbocharger dengan daya keluaran yang sama 1,9 MW, putaran mesinnya sama dengan sebelum pemeliharaan 503 rpm, frekuensi getaran naik dari sebelum pemeliharaan 49,8 $\mathrm{Hz}$ setelah pemeliharaan naik menjadi 50,13 Hz, dan untuk putaran turbocharger setelah overhoul turun menjadi 11. $500 \mathrm{rpm}$ dari 12. $500 \mathrm{rpm}$. Kemudian temperatur gas setelah pembakaran di dalam silinder 1 sampai 6 sisi A rata - rata $301{ }^{\circ} \mathrm{C}$ dan B $289{ }^{\circ} \mathrm{C}$, terjadi penurunan temperatur hasil pembakaran dari sebelumnya di sisi A rata - rata $332{ }^{\circ} \mathrm{C}$ dan di B rata - rata $323{ }^{\circ} \mathrm{C}$ 


\section{4. Beban Keluaran unit 3,7 MW Sebelum dan Setelah Overhaul Turbocharger}

Data sebelum dilakukan pemeliharaan overhoul turbocharger untuk daya untuk daya 3,8 MW adalah putaran mesin 502 rpm, frekuensi getaran 49,92 Hz, dan untuk putaran turbocharger adalah $14.500 \mathrm{rpm}$, untuk temperatur gas setelah pembakaran di dalam silinder 1 sampai 6 sisi A rata rata $386^{\circ} \mathrm{C}$ dan sisi B $373{ }^{\circ} \mathrm{C}$, temperatur gas buang masuk ke dalam turbin turbocharger sisi A $381^{\circ} \mathrm{C}$ dan keluar dari turbin $348^{\circ} \mathrm{C}$, sisi $\mathrm{B}$ turbin turbocharger udara gas buang masuk $396^{\circ} \mathrm{C}$ dan keluar turbin $362^{\circ} \mathrm{C}$.

Kemudian setelah dilakukan pemeliharaan overhoul turbocharger dengan daya keluaran yang sama 3,8 MW, putaran mesinnya turun menjadi $500 \mathrm{rpm}$ dari sebelumnya $503 \mathrm{rpm}$, frekuensi getaran naik dari sebelum pemeliharaan 49,92 $\mathrm{Hz}$ kemudian setelah pemeliharaan naik menjadi $50,1 \mathrm{~Hz}$, dan untuk turbocharger speed L/R (kiri/kanan) setelah overhoul turun menjadi $13.500 \mathrm{rpm}$ dan 13.000 rpm dari 14.500 rpm. Kemudian temperatur gas setelah pembakaran di dalam silinder 1 sampai 6 sisi A rata rata $364^{\circ} \mathrm{C}$ dan $\mathrm{B} 347^{\circ} \mathrm{C}$, terjadi penurunan temperatur hasil pembakaran dari sebelumnya di A sebesar $387^{\circ} \mathrm{C}$ dan B sebesar $373{ }^{\circ} \mathrm{C}$.

\subsection{Beban Keluaran unit 5,7 MW Sebelum dan Setelah Overhaul Turbocharger}

Data sebelum dilakukan pemeliharaan overhoul turbocharger untuk daya 3,8 MW adalah putaran mesin $504 \mathrm{rpm}$, frekuensi getaran $50,11 \mathrm{~Hz}$, dan putaran turbocharger adalah $18.000 \mathrm{rpm}$. Untuk temperatur gas setelah pembakaran di dalam silinder 1 sampai 6 sisi A rata rata $420^{\circ} \mathrm{C}$ dan sisi $\mathrm{B} 411^{\circ} \mathrm{C}$, temperatur gas buang masuk ke dalam turbin turbocharger sisi A $443^{\circ} \mathrm{C}$ dan keluar dari turbin $368{ }^{\circ} \mathrm{C}$, sisi $\mathrm{B}$ turbin turbocharger udara gas buang masuk $457^{\circ} \mathrm{C}$ dan keluar turbin $377^{\circ} \mathrm{C}$.

Kemudian setelah dilakukan pemeliharaan overhoul turbocharger dengan daya keluaran yang sama 5,7 MW, Putaran mesinnya turun menjadi 503 rpm dari sebelumnya 504 rpm, frekuensi getaran naik dari sebelum pemeliharaan 50,11 $\mathrm{Hz}$ kemudian setelah pemeliharaan turun menjadi 50,04 Hz dan masih dalam batas normal penurunan, dan untuk turbocharger speed L/R setelah overhoul turun menjadi 17.000 rpm dari 18.000 rpm. Kemudian temperatur gas setelah pembakaran di dalam silinder 1 sampai 6 sisi A rata rata $399^{\circ} \mathrm{C}$ dan B $407^{\circ} \mathrm{C}$ dari sebelumnya di A sebesar $430^{\circ} \mathrm{C}$ dan di B sebesar $420^{\circ} \mathrm{C}$. Pada silinder sisi B tidak terlalu terjadi penurunan temperatur pembakaran hal ini disebabkan karena pada silinder sisi B ada komponen yang terjadi gangguan pada saat pengambilan data ini. Gangguan ini biasanya terjadi disebabkan oleh bocor kompresi atau pun pengabutan bahan bakar oleh nozzle ring kurang sempurna.

\subsection{Perbandingan Data Saat Beban 1,9 MW, 3,8 MW dan 5,7 MW}

Penurunan putaran turbocharger yang dibutuhkan untuk beban yang sama pada setelah overhaul turbocharger disebabkan: ringannya putaran dari turbin dan kompresor; lebih bersihnya udara yang masuk ke saluran turbocharger; lebih bersihnya saluran masuk yang menyebabkan turunnya gaya gesek udara terhadap saluran. Hal - hal tersebut terjadi karena untuk kebutuhan beban yang sama, putaran kompresi yang diperlukan untuk memasok udara (dengan kondisi yang cukup untuk beban yang sama) ke dalam ruang bakar untuk meningkatkan kinerja mesin setelah overhoul turbocharger karena pembersihan bagian - bagian turbocharger dan penggantian bearing, sehingga dari data di atas. Sebagai contohnya: beban 1,9 MW tercapai dengan hanya putaran turbocharger $11.500 \mathrm{rpm}$ dibandingkan yang sebelumnya (sebelum overhaul turbocharger) $12.500 \mathrm{rpm}$.

Putaran mesin yang menurun setelah overhaul turbocharger disebabkan oleh dengan putaran mesin yang relatif lebih rendah pada nilai beban generator yang sama. Hal ini terjadi karena putaran mesin yang dibutuhkan adalah seolah - olah lebih tinggi daripada sebelum overhaul turbocharger. Hal ini disebabkan oleh kotornya sensor putaran mesin diesel. Sensor putaran umumnya bekerja dengan produksi voltase atau arus listrik yang disesuaikan dengan putaran mesin. Semakin cepat putaran mesin, semakin tinggi arus atau voltase yang terdeteksi reseptor sensor. Saat kalibrasi, sensor "disetting" referensinya untuk putaran x rpm, nilai voltase atau arus sekian; lalu untuk putaran y rpm, nilai voltase atau arus sekian; dst. Pada saat kalibrasi juga, sensor dalam keadaan bersih. Ketika sensor kotor, untuk putaran yang sama, sensor menghasilkan voltase yang lebih rendah karena ada penghalang - penghalang berupa debu - debu, fouling akibat persenyawaan, dsb. yang menghalangi sensor memproduksi arus atau voltase, sehingga untuk mencapai referensi 
voltase yang sama, sensor membutuhkan rpm mesin yang lebih tinggi. Voltase atau arus ini dihubungkan ke pengendalian sistem sensorik yang membaca voltase atau arus listrik dengan penetapan (misal) beban keluaran unit setara dengan referensi sekian volt atau ampere di sensor, sehingga untuk beban yang sama, seolah - olah dibutuhkan putaran mesin yang lebih tinggi.

Getaran mesin ada yang naik setelah overhaul turbocharger, tetapi ada juga yang turun. Kenaikan dan penurunannya tidak signifikan. Getaran mesin diesel terjadi akibat ketidakseimbangan bentuk mesin (dan kotoran kotoran yang ada), dan umumnya berubah ubah sepanjang rentang rpm mesin. Untuk kenaikan dan penurunan getaran mesin yang terjadi setelah overhaul turbocharger adalah masuk di akal dan kondisi mesin secara dasarnya baik - baik saja karena bila ada kegagalan/kerusakan yang fatal, getaran mesin biasanya akan bertambah signifikan. Getaran mesin yang meningkat setelah overhaul biasanya terjadi karena bagian - bagian mesin jadi lebih ringan karena mesin lebih bersih, sehingga berat mesin (peredam getaran) berkurang, maka gaya yang sama pada mesin bisa menggetarkan lebih tinggi karena mesin lebih ringan.

Penurunan temperatur hasil pembakaran setelah overhaul turbocharger disebabkan oleh pemeliharaan intercooler, sehingga transfer kalor udara yang telah melewati kompresor turbocharger dengan fluida pendinginannya menjadi lebih baik, sehingga suhu udara sebelum masuk ruang bakar lebih rendah. Suhu yang lebih rendah ini menyebabkan udara terbakar pada suhu yang lebih rendah, sehingga temperatur hasil pembakaran lebih rendah.

\section{KESIMPULAN}

1. Penurunan putaran turbocharger yang dibutuhkan untuk beban yang sama setelah overhaul turbocharger disebabkan: ringannya putaran dari turbin dan kompresor karena penggantian bagian bagiannya, pembersihan, dsb. Sebagai contohnya: beban 1,9 MW hanya perlu $11.500 \mathrm{rpm}$ dibandingkan yang sebelumnya (sebelum overhaul turbocharger) 12. 500 rpm.

2. Penurunan putaran mesin setelah overhaul turbocharger untuk beban yang sama disebabkan putaran mesin yang dibutuhkan adalah seolah - olah lebih tinggi daripada sebelum overhaul turbocharger. Hal ini disebabkan oleh kotornya sensor putaran mesin diesel, sehingga produksi voltase atau arus sensor putaran mesin menurun.

3. Getaran mesin ada yang naik setelah overhaul turbocharger. Getaran mesin yang meningkat setelah overhaul biasanya terjadi karena bagian - bagian mesin jadi lebih ringan karena mesin lebih bersih, sehingga gaya berat mesin (peredam getaran) berkurang, maka getaran mesin meningkat.

4. Penurunan temperatur hasil pembakaran setelah overhaul turbocharger disebabkan oleh pemeliharaan intercooler, sehingga transfer kalor udara yang telah melewati kompresor turbocharger dengan fluida pendinginannya menjadi lebih baik, sehingga suhu udara sebelum masuk ruang bakar lebih rendah.

5. Pencegahan surging dengan cara pembersihan intercooler agar tekanan udara setelah melalui kompresor turbocharger tidak terlalu tinggi akibat kemampuan pendinginan udara oleh intercooler kurang baik.

\section{DAFTAR PUSTAKA}

[1] Anonim, 1996, Technical Information ABB Turbocharging Operating Turbocharging : Collection of Articles by Johan Schiemen, Turbo magazine 1992 - 1996.

[2] Anonim, 2012, ABB Turbocharging: We Multiply Power, ABB, Turbo System Ltd, Baden,Switzerland.

[3] Ballaney, P. L.. 1986. Internal Combustion Engine in Theory and Practice. Delhi: Khanna.

[4] DeLeon, Christopher. Tanpa tahun. Turbocharger and How It Works. Gredy. 2007. Total Tune - Up: Performance Part, (Online),

[5] Edward F. Obert, "Internal Combustion Engines", third edition, Scranton, Pennsylvania, 1968.

[6] Ganeson, V.. 2006. Internal Combustion Engine. New Delhi: Tata Mc-Graw Hill.

[7] Heywood, John B.. 1988. Internal combustion Fundamentals. McGraw-Hill Inc. 
[8] Kristanto, Philip. 2015. Buku Motor Bakar Torak (Teori dan Aplikasi). Jakarta: Penerbit Andi.

[9] Petrovsky, N., "Marine Internal Combustion Engine", Mir Publisher, Moscow, 1988.

[10] Wibowo, Fendi Adi. Perawatan Turbo Charger untuk Menunjang Kinerja Mesin Penggerak Utama di KM. Nusantara Pelangi 02 PT Jatim Perkasa Line.http://fendiadiwibowo.blogspot.co.id/ 2017/01/materi-karya-tulis-perawatanturbo.html. Diakses pada 18 Desember 2017.

[11] Murwanto, Anwar Dwi. (2014). Pemanfaatan Gas Buang Hasil Pembakaran untuk Induksi Paksa Langkah Hisap Motor Diesel Sistem Turbocharger. Yogyakarta.

[12] http://lokerpelaut.com/point-point-pentinguntuk-efisiensi-turbocharger.html. Diakses pada 18 Desember 2017 pukul 09:16.

[13] http://www.imareindonesia.org/?p=338. Diakses pada 18 Desember 2017 pukul 09:21. 